\title{
THE IMPLEMENTATION OF RISK MANAGEMENT OF FOREIGN EXCHANGE INVESTMENT AT PT. BEST PROFIT FUTURES MALANG
}

\author{
Ulfa Puspitasari \\ Department of Management FEB UMM \\ E-mail: fifipipik@gmail.com
}

\begin{abstract}
This study aimed (1) to determine the risk of forex investments and (2) to figure out the implementation of risk management on forex. This study used descriptive method to examine a brokerage firm located in Malang named PT Best Profit Future Malang. Based on the results, it was found that the risks in forex investment were a floating risk of market circumstances, price change, overnight, interest rates and political event. The analysis used to determine the volatility of the forex market were technical and fundamental analysis. Technical analysis used an accurate historical rates and calculations whereas fundamental analysis used information and market news. Forex investment had a high investment risk if market volatility was not favorable, so the risk management was urgently required. Therefore, there were five risk managements; hold, aver4age, limit loss/locking, switching, and cut loss.
\end{abstract}

Keywords: forex risk, risk management

\section{PENDAHULUAN}

Salah satu investasi saat ini yang memberikan keuntungan tinggi namun juga berisiko tinggi adalah investasi yang bergerak di bidang perdagangan valuta asing, yaitu Foreign Exchange. Sekarang ini banyak yang mulai percaya bahwa bisnis trading online ini sangatlah menjanjikan. Trading forex ini bisa dianggap sebagai pekerjaan mereka setiap harinya.

Foreign Exchange merupakan perdagangan mata uang dua negara yang berbeda nilainya secara longitudinal. Perputaran uang yang terjadi pada pasar foreign exchange lebih besar jika dibandingkan dengan perputaran uang pada pasar lainnya. Perputaran uang pada forex tersebut mencerminkan volume perdagangan komoditi yang bersifat liquid (cair), kendali perdagangan tidak dapat dipegang oleh hanya beberapa pihak yang memiliki modal besar.

Kenyataan yang terjadi di lapangan menegaskan bahwa masih terdapat permasalahan yang timbul yaitu masih banyaknya nasabah baru yang mengeluhkan tentang investasi forex ini. Pendatang baru harus benar-benar memahami teknikteknik dalam melakukan investasi, sehingga mereka dapat mengurangi resiko yang ada dan tidak hanya tergiur oleh keuntungan semata.

PT Bestprofit Futures Cabang Malang memberikan kemudahan bagi investor untuk memilih sendiri jenis investasi dan transaksi yang 
diinginkan oleh investor serta investor dapat melakukan transaksi sendiri. Hal ini merupakan langkah awal dalam meminimalisir terjadinya risiko dan membiasakan investor untuk lebih berhati-hati ketika bertransaksi dan tidak hanya mengharapkan untung saja.

Langkah awal ini memang sudah rutin dilakukan oleh PT Bestprofit Futures Cabang Malang dan ditunjang oleh adanya Business Consultant $(B C)$ yang siap membantu dalam melakukan trading forex, namun masih terdapat nasabah yang berulang kali mengalami loss hingga menutup akun tradingnya. Para nasabah yang mengalami loss ini akhirnya kembali menyalahkan PT Bestprofit Futures Cabang Malang sebagai broker atas kebangkrutan yang dialaminya, sehingga memberikan dampak terhadap penurunan reputasi perusahaan.

Tujuan dalam penelitian ini adalah untuk mengetahui risikorisiko dalam melakukan transaksi forex pada PT Bestprofit Futures Cabang Malang serta untuk menjelaskan implementasi manajemen risiko pada PT Bestprofit Futures Cabang Malang dalam melakukan transaksi foreign exchange.

\section{TINJAUAN PUSTAKA}

Manajemen risiko adalah suatu kegiatan pelaksanaan fungsi-fungsi dari manajemen dalam hal penanggulangan resiko, terutama resiko-resiko yang dihadapi oleh organisasi atau perusahaan, keluarga dan masyarakat. Manajemen Risiko mencakup kegiatan merencanakan, mengorganisir, kegiatan menyusun, memimpin atau mengkoordinir dan mengawasi (termasuk mengevaluasi) program-program penanggulangan resiko (Djojosoedarso, 2003:4).

Pengelolaan risiko dengan memanajemen risiko yang mantap, maka pengaturan potensi kerugian tersebut dapat dilakukan. Manajemen risiko di sini pada prinsipnya dilakukan dengan mengaktifkan fasilitas-fasilitas dalam Forex Trading (Budi, 2008:132).

Ada beberapa cara yang dapat dilakukan untuk manajemen risiko diantaranya adalah sebagai berikut (Budi, 2008:133). Pertama, cut loss yaitu suatu tindakan di mana kita melakukan likuidasi atas posisi dalam keadaan rugi. Kedua, switching yaitu, tindakan dimana kita melakukan liquidasi terhadap posisi pertama, kemudian masuk kembali dengan posisi yang berlawanan dari posisi pertama tadi. Ketiga adalah locking, yaitu tindakan mengunci kerugian atau keuntungan tersebut dengan posisi yang berlawanan dengan posisi pertama. Keempat adalah averaging yaitu suatu tindakan mengulangi posisi yang sama pada saat kita dalam keadaan floating loss, dimana posisi pertama dibiarkan terbuka.

Terdapat analisis fundamental dan analisis teknikal Analisis teknikal berdasarkan pada pola-pola pergerakan dari waktu ke waktu, sedangkan analisis fundamental mendasarkan diri pada faktor-faktor fundamental perusahaan yang dipengaruhi oleh faktor ekonomi (Tandelilin, 2001:247).

Trading Forex adalah perdagangan mata uang dari negara yang berbeda. Kondisi pasar dan harga dalam pasar foreign exchange 
bergerak dengan sangat dinamis dan berubah cepat, dalam menanggapi peristiwa-peristiwa baik itu ekonomi, politik, perang, maupun bencana. (http://www.seputarforex.com).
Berdasarkan teori- teori dan penilitian terdahulu yang telah dijelaskan sebelumnya, maka dapat digambarkan dalam kerangka pemikiran sebagai berikut:

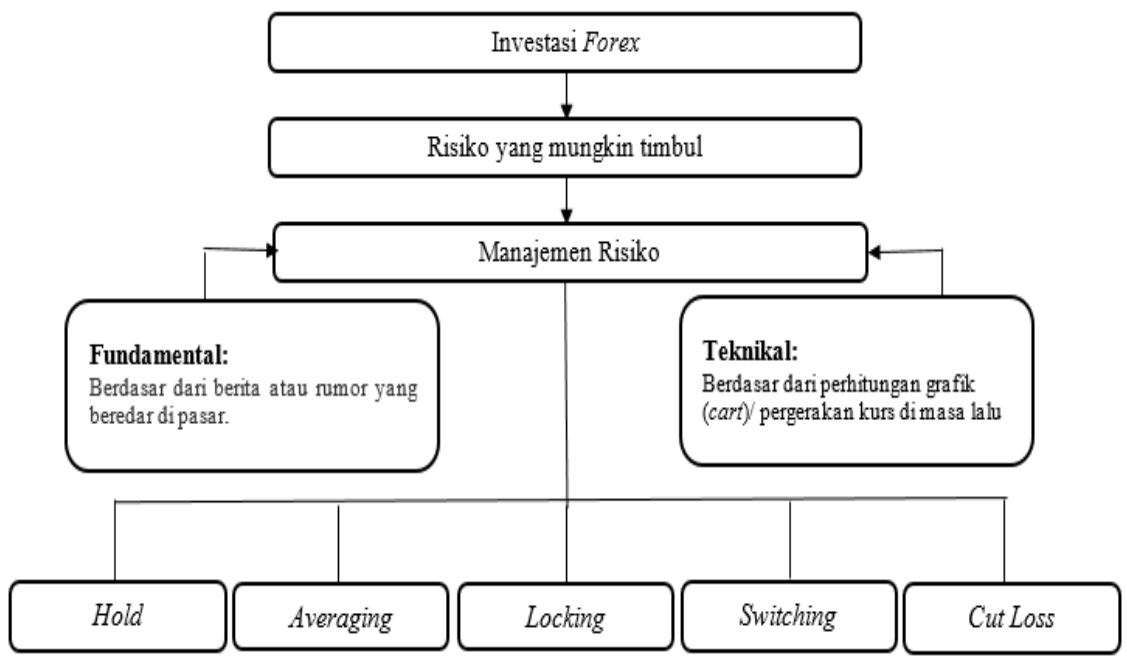

Gambar 1. Kerangka Pikir Penelitian

\section{METODE PENELITIAN}

Lokasi penelitian adalah PT Bestprofit Futures Cabang Malang.Jenis penelitian yang digunakan dalam penelitian ini adalah kualitatif deskriptif. Penelitian kualitatif deskriptif adalah penelitian deskriptif yang berusaha mengumpulkan, menerapkan dan menyajikan data-data disertai analisis dan interpretasi sehingga memberi gambaran yang cukup jelas tentang objek yang diamati.

Data yang dinyatakan dan disajikan dalam bentuk data deskriptif berupa kata, kalimat dan gambar, yang membahas tentang macam-macam risiko dalam forex dan bagaimana penerapan manajemen risiko pada investasi Foreign Exchange (Forex).

Jenis data yang digunakan dalam penelitian ini adalah data primer dan data sekunder. Teknik pengumpulan data yang digunakan pada penelitian ini adalah wawancara di PT Bestprofit Futures Cabang Malang. Teknik kedua adalah dokumentasi. Dokumentasi pada penelitian ini berupa laporan forex di PT Bestprofit Futures Cabang Malang, grafikgrafik dan harga-harga forex yang berhubungan dengan perdagangan forex.

Teknik analisis data yang digunakan adalah yang pertama dalam manajemen risiko yaitu dengan mengidentifikasi risiko dengan menggunakan analisis data historis dari PT Bestprofit Future Cabang Malang. Langkah kedua dalam manajemen risiko yaitu mengukur risiko. Pengukuran risiko dilakukan dengan mengukur Volatilitas pasar. Pengukuran volatilitas pasar dilakukan dengan analisis teknikal dan analisis fundamental. 
Analisis teknikal mendasarkan pada kilas balik atas harga dalam perdagangan historis dan melihat kecenderungan harga di pasar, menggunakan rumus pivot point, yaitu (PT Bestprofit Future Cabang Malang):

$$
P P=\frac{(H+L+C)}{3}
$$

Yang mana PP adalah pivot point, $\mathrm{H}$ adalah high, L adalah low, $\mathrm{C}$ adalah $L$ dikali Trade. Langkah selanjutnya menentukan R (Batas Atas) dan $S$ (Batas Bawah), untuk rumus dari $\mathrm{R}$ dan $\mathrm{S}$ adalah sebagai berikut:

$$
\begin{gathered}
R_{1}=(2 x P P)-L \\
R_{2}=P P+\left(R_{1}-S_{1}\right)
\end{gathered}
$$

Yang mana $R$ adalah batas atas, $\mathrm{PP}$ adalah pivot point, $\mathrm{L}$ adalah low, $\mathrm{H}$ adalah high, $\mathrm{S}$ adalah batas bawah. Batas bawah dapat dihitung menggunakan formula berikut:

$$
\begin{aligned}
& S_{1}=(2 x P P)-H \\
& S_{2}=P P-(H-L)
\end{aligned}
$$

Pengukuran pivot point ini menggunakan ketentuan sebagai berikut, $\mathrm{PP}<$ Open market menunjukkan jika pasar dalam kondisi kecenderungan Sell dimana jika mengambil Buy kecenderungan beresiko. PP > Open market menunjukkan jika pasar dalam kecenderungan Buy dimana jika mengambil Sell kecenderungan beresiko.

Analisis fundamental sendiri berdasarkan pada berita-berita, atau rumor yang terjadi di pasar. Langkah selanjutnya yaitu menentukan manajemen risiko yaitu dengan cut loss, switching maupun dengan averaging. Manajemen risiko ini untuk mengetahui sejauh mana pengelolaan risiko terhadap risiko yang muncul dalam forex.

\section{HASIL PENELITIAN DAN PEMBAHASAN}

PT. Bestprofit Future adalah sebuah perusahaan yang bergerak dibidang jasa keuangan non perbankan yang menyediakan fasilitas investor untuk bertransaksi di BBJ (Bursa Berjangka Jakarta). Perusahaan ini menyediakan fasilitas berupa trading forex, indeks saham, dan komoditi dengan spread yang kompetitif. PT Bestprofit Future berada di bawah regulasi BAPPEBTI (Badan Pengawas Perdagangan Berjangka Komoditi) dengan izin nomor 499/BAPPEBTI/SI/X/2004.

Pada PT Bestprofit Futures Cabang Malang, risiko yang dihadapi pada investasi forex ini adalah risiko floating. Risiko floating di sini memiliki faktor penyebabnya. Faktor tersebut diantaranya adalah keadaan pasar, perub ahan harga, overnight, event politik. Pada faktor keadaan pasar ini, investor tidak dapat melakukan apa-apa kecuali mampu mengenal dan juga menganalisis untuk mengatasinya.

Perubahan harga merupakan risiko dikarenakan mata uang yang ada dalam perdagangan forex terkadang bergerak stabil namun terkadang berfluktuasi. Perubahan harga ini menyebabkan investor mengganti batasan transaksi. Overnight merupakan risiko investor terkadang tidak dapat melakukan order ketika pasar foreign exchange tutup, sehingga posisi overnight 
dipertimbangkan oleh investor. Event politik, yaitu risiko yang berkaitan dengan faktor keamanan suatu negara karena keadaan politik. Pasar forex merupakan pasar yang paling responsif terhadap event politik.
Pivot point sendiri merupakan salah satu analisis teknikal yang paling mudah yang dapat digunakan untuk memperkirakan pasar hari berikutnya. Pivot Point akan ditampilkan pada Tabel 1 berikut ini:

Tabel 1. Contoh Pivot Point PT. Bestprofit Futures Cabang Malang.

\begin{tabular}{ccccccccc}
\hline Name & High & Low & Close & $\begin{array}{c}\text { Pivot } \\
\text { Point }\end{array}$ & $R_{l}$ & $R_{2}$ & $S_{l}$ & $S_{2}$ \\
\hline JPY & 114,05 & 112,69 & 113,65 & 113,46 & 114,23 & 114,82 & 112,87 & 112,10 \\
AUD & 0,7700 & 0,7632 & 0,7675 & 0,7669 & 0,7706 & 0,7737 & 0,7638 & 0,7601 \\
EUR & 1,0589 & 1,0513 & 1,0545 & 1,0549 & 1,0585 & 1,0625 & 1,0509 & 1,0473 \\
GBP & 1,2405 & 1,2279 & 1,2284 & 1,2323 & 1,2367 & 1,2449 & 1,2241 & 1,2197 \\
CHF & 1,0129 & 1,0050 & 1,0088 & 1,0089 & 1,0128 & 1,0168 & 1,0049 & 1,001 \\
\hline
\end{tabular}

Pivot point di atas dilihat kisaran nilai PP seperti pada forex AUD yaitu pada point 0.7669 . Nilai point pada open hari selanjutnya sebesar 0.7676, maka nilai open market lebih besar daripada pivot point $(\mathrm{O}>\mathrm{PP})$ maka investor diajurkan untuk melakukan sell new. Perhitungan hasil volatilitas pasar menggunakan teknikal pivot point akan ditampilkan secara rinci oleh Tabel 2 sebagai berikut:

Tabel 2. Teknikal terhadap volatilitas Pivot Point

\begin{tabular}{lccc}
\hline Name & $\begin{array}{c}\text { Pivot } \\
\text { Point }\end{array}$ & $\begin{array}{c}\text { Open hari } \\
\text { selanjutnya }\end{array}$ & Keterangan \\
\hline JPY & 113,46 & 113,71 & Sell New \\
AUD & 0,7669 & 0,7676 & Sell New \\
EUR & 1,0549 & 1,0544 & Buy New \\
GBP & 1,2323 & 1,2294 & Buy New \\
CHF & 1,0089 & 1,0089 & Sell- Buy New \\
\hline
\end{tabular}

Perkiraan volatilitas pasar diketahui bahwa nilai forex JPY dan AUD mengalami sinyal turun. Pada forex EUR dan GBP menunjukkan bahwa mengalami sinyal naik. Forex CHF berada pada posisi nilai tengah pivot point sehingga dapat bergerak naik maupun turun. Analisis selanjutnya yaitu analisis fundamental adalah pendekatan melalui berita-berita ekonomi atau rumor yang ada di pasar. 


\begin{tabular}{lllllll}
\multicolumn{7}{l}{ MARKET CALENDAR } \\
\hline Time & Country & Im & Figures & Previous & Forecast & Actual \\
\hline 15.30 & GBP & M & Public Sector Net Borrowing & $1.1 \mathrm{~B}$ & $2.6 \mathrm{~B}$ & $4.4 \mathrm{~B}$ \\
\hline 20.00 & EUR & L & Belgian NBB Business Climate & -1.6 & -1.4 & \\
\hline 20.00 & U.S & L & HPI m/m & $0.0 \%$ & $0.1 \%$ \\
\hline 20.00 & U.S & L & S\&P/CS Composite-20 HPI y/y & $5.7 \%$ & $5.7 \%$ & \\
\hline 21.00 & U.S & H & CB Consumer Confidence & 125.6 & 123.7 & \\
\hline 21.00 & U.S & M & New Home Sales & $592 \mathrm{~K}$ & $590 \mathrm{~K}$ & \\
\hline 21.00 & U.S & L & Richmond Manufacturing Index & 22 & 18 & \\
\hline All Day & EUR & L & Italian Bank Holiday & - & -
\end{tabular}

Gambar 2. Contoh berita analisis fundamental

Investor dapat melihat analisis fundamental tersebut dengan mengklik berita fundamental. Apabila actual bernilai lebih besar dari forecast maka kecenderungan harga mahal. Prediksi kurs Euro akan mengalami kenaikan, lalu investor tersebut mengambil posisi buy new EU1010_BBJ pada harga 1.0573 sebanyak 2 lot. Tidak lama kemudian nasabah akan melikuidasi posisi terbuka pada harga 1.0568 sebanyak 2 lot karena ternyata harga Euro mengalami penurunan harga.

Maka risiko kerugian nasabah dapat dihitung dengan formula $[($ selling price - buying price) $\mathrm{x}$ contract size $\mathrm{x} \mathrm{n}$ lot $]-[($ commission + VAT) x $\mathrm{n}$ lot ]. Dengan perhitunggan menggunakan formula tersebut dihasilkan angka \$166. Sehingga dapat dikatakan bahwa, nasabah mendapatkan risiko sebesar US\$166 atau Rp 1.660.000,00 (Fixed rate $\mathrm{US} \$ 1=\mathrm{Rp} 10.000,00)$.

Manajemen risiko yang diterapkan oleh PT Bestprofit Futures meliputi hold, average, limit loss (locking), switching dan cut loss (stop loss). Manajemen risiko Hold (Menahan Posisi) pada point 1285, diambil posisi buy new sebanyak 1 lot kemudian market mengalami penurunan, seperti pada point 1280 , tapi analisis fundamental masih bersifat positif, maka investor bisa menerapkan manajemen risiko hold.

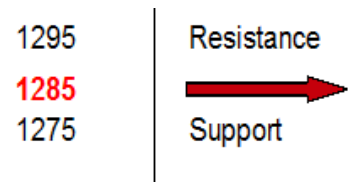

Gambar 3. Ilustrasi Manajemen Risiko Hold

Manajemen risiko Average, pada point 1285 investor mengambil posisi buy new 1 lot kemudian market mengalami penurunan ke point 1280. Investor mengambil posisi baru yaitu buy new lagi dengan 2 lot. Investor memiliki posisi lepas yaitu $(1285+1280): 2$ dan memperoleh hasil 1282.50.

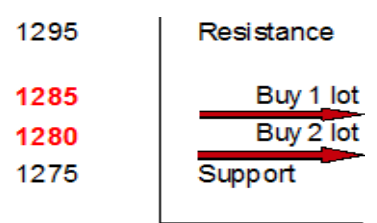

Gambar 4. Ilustrasi Manajemen Risiko Average

Manajemen risiko Limit Loss (Membatasi Kerugian Posisi) pada point 1285 investor mengambil posisi buy new sebanyak 1 lot, 
market mengalami penurunan, didukung oleh berita fundamental yang negatif, maka investor bisa mengambil posisi sell new sebanyak 1 lot juga.

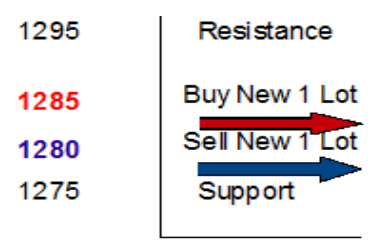

Gambar 5. Ilustrasi Manajemen Risiko Limit Loss

Manajemen risiko Switching (Merubah Arah Posisi) pada point 1285, investor mengambil posisi buy new sebanyak 1 lot kemudian market mengalami penurunan, dan berita fundamental yang negatif, maka investor mengambil posisi sell new sebanyak 2 lot atau lebih.

\begin{tabular}{l|l}
1295 & Resistance \\
1285 & Buy New 1 Lot \\
1280 & Sell New 2 Lot \\
1275 & Support
\end{tabular}

Gambar 6. Ilustrasi Manajemen Risiko Switching

Manajemen risiko Cut Loss (Melepas Posisi Rugi) yaitu aksi menutup posisi akun investor yang berlawanan dengan pergerakan harga pasar. Cut loss tidak dianjurkan untuk dilakukan apabila masih memungkin untuk melakukan manajemen risiko yang lainnya.

Berdasarkan analisis data yang telah dilakukan, maka hasil penelitian ini akan dijelaskan sebagai berikut. Risiko merupakan hal yang akan mengekor dan menjadi suatu ketakutan pada setiap orang yang ingin berinvestasi. Risiko ini maksudnya adalah jika sesorang sudah memilih untuk melakukan investasi, apapun jenisnya, maka akan selalu ada risiko yang akan dihadapi.

Pada PT Bestprofit Futures Cabang Malang, risiko floating-lah yang menjadi satu-satunya risiko yang harus diperhatikan. Risiko floating memiliki banyak faktor penyebab yaitu keadaan pasar, perubahan harga, overnight, suku bunga dan event politik. Beberapa orang mengatakan faktor ini merupakan risiko, namun dalam PT Bestprofit Futures Cabang Malang, kelima faktor tersebut masuk dalam risiko floating, karena kelima faktor tersebut menyebabkan terjadinya nilai mengambang pada investasi forex.

Hasil penelitian risiko ini sesuai dengan penelitian yang dilakukan Indrawati (2008) dan Kusumasari (2011) yang menunjukkan bila risiko yang ada pada investasi foreign exchange adalah risiko perubahan harga yang mengambang (naik atau turun) dengan faktor-faktor yang menyebabkan keadaan tersebut. Secara teori, faktor-faktor dari risiko floating termasuk risiko yang mungkin timbul dan perlu dipertimbangkan dalam pembuatan keputusan investasi (Halim, 2003:39).

Terkait dengan risiko forex di atas, PT Bestprofit Futures Cabang Malang mempunyai solusi untuk meminimalisir risiko yang terjadi dan memaksimalkan profit yang didapat. Solusi ini berupa manajemen risiko. Sebelum para investor melakukan transaksi dalam forex, perusahaan akan memberikan pengarahan dan pelatihan yang berhubungan dengan manajemen 
risiko dan teknik-tekniknya untuk menghadapi pasar. Analisa ini terdapat analisa teknikal (pivot point) dan fundamental.

Penggunaan analisis teknikal dan fundamental digunakan sebagai dasar pengambilan keputusaan. Sebenarnya analisis tersebut tidak mutlak $100 \%$ bisa menghilangkan risiko, keakuratan dari pemakaian analisis tersebut berkisar antara $70 \%$ sampai dengan $80 \%$.

Investasi forex memiliki lima manajemen risiko dimulai dari hold (menahan posisi) untuk kisaran perbedaan point 1-5, average (meratakan posisi) untuk kisaran point 5-10. Selanjutnya ada limit loss (membatasi kerugian posisi) untuk kisaran point 5-10, switching (merubah arah posisi) yang memiliki cara yang serupa dengan limit loss. Manajemen risiko terakhir ada cut loss (melepas posisi rugi) apabila point lebih dari 10.

Manajemen risiko yang sering digunakan oleh PT Bestprofit Futures Cabang Malang adalah cut loss dan hold. Cut loss adalah ketika memesan harga tertentu seandainya running menyentuh harga tersebut maka posisi point akan tertutup secara otomatis dengan posisi rugi, adapun kelebihannya adalah bisa membatasi kerugian. Sedangkan hold adalah menunggu pergerakan harga sampai sesuai dengan keinginan.

Investor pun yang ingin bertrading forex di PT Bestprofit Futures selalu ditekankan adanya cutt loss karena dengan memasang cut loss bisa mencegah dan menjaga dari hal-hal yang tidak diinginkan. Cut loss merupakan salah satu manajemen risiko yang paling digemari oleh investor, karena dengan melakukan cut loss tersebut maka kerugian dan keuntungan yang diperoleh bisa dibatasi dan hal itu juga merupakan salah satu etika yang baik dalam melakukan investasi di forex. Hal ini dikarenakan dengan membatasi kerugian dan keuntungan, investor dapat terhindar dari sifat serakah.

Hasil penelitian ini sesuai dengan penelitian yang dilakukan oleh Indrawati (2008) yang menyatakan bahwa manajemen risiko yang diterapkan pada investasi forex adalah cut loss, switching, locking, dan averaging serta manajemen risiko yang paling sering digunakan adalah pemasangan cut loss dengan berpatokan pada analisis yang digunakan yaitu berdasarkan analisis teknikal dan fundamental.

Pengelolaan risiko dengan memanajemen risiko yang mantap, maka pengaturan potensi kerugian tersebut dapat dilakukan. Manajemen risiko di sini pada prinsipnya dilakukan dengan mengaktifkan fasilitas-fasilitas dalam forex trading, seperti Cut loss (menghentikan kerugian) dan Locking (mengunci posisi dari kerugian/keuntungan) (Budi 2008:132). Ada beberapa cara untuk manajemen risiko diantaranya adalah cut loss, switching, locking dan averaging (Budi, 2008:133).

\section{KESIMPULAN}

Berdasarkan hasil penelitian dan uraian pembahasan yang telah dikemukakan pada paragraf-paragraf sebelumnya maka dapat disimpulkan bahwa, risiko yang terjadi saat melakukan trading di pasar forex adalah risiko floating. Risiko floating berdampak pada bergeraknya grafik yang mempengaruhi posisi investor. 
Manajemen risiko yang diterapkan di PT Bestprofit Future Cabang Malang dalam menghadapi risiko floating, yaitu Hold, Average, Locking, Switching, dan Cut loss, dan dari kelima manajemen risiko yang ada, manajemen risiko yang sering dipakai di PT Bestprofit Futures adalah pemasangan Cut loss dan Hold.

Penelitian ini telah diusahakan dan dilaksanakan sesuai dengan prosedur ilmiah, namun demikian masih memiliki keterbatasan yaitu: Indikator analisis teknikal hanya menggunakan indikator pivot point, objek yang digunakan adalah forex atau mata uang saja, masih terdapat banyak perusahaan pialang yang terdaftar di BAPPEBTI dan KBI di seluruh Indonesia

Berdasarkan hasil penelitian dan pembahasan, ada beberapa saran yang diharapkan bermanfaat bagi:

Bagi Perusahaan. Mekanisme transaksi Forex di PT Bestprofit Futures, disarankan agar tetap memegang sifat keterbukaan kepada calon nasabah untuk selalu memberikan penjelasan teknikal dan fundamental tentang risiko dan cara memanajemenkan risiko yang berhubungan dengan perdagangan berjangka, sehingga dari pihak investor juga diharapkan mengerti bahwa investasi ini bukan sekedar main-main saja dan juga harus selalu konsisten dalam melakukan transaksi forex.

Bagi Investor yang ingin berinvestasi di bidang ini, sebelum melakukannya sebaiknya terlebih dahulu memahami dan juga bisa mengelola risiko dengan baik. Berdasarkan penelitian, manajemen risiko yang disarankan untuk dipakai adalah Cut loss dan Hold, karena dengan mengunakan manajemen risiko tersebut bisa membatasi risiko dan mengelola profit dengan benar.

Bagi Peneliti Selanjutnya, sebaiknya menggunakan indikator teknikal maupun fundamental yang berbeda dengan objek diluar dari forex namun masih dalam lingkup perdagangan berjangka. Disarankan pula penelitian lain yang sejenis tetapi dengan materi atau konsep lain dalam ruang lingkup yang lebih luas.

\section{DAFTAR PUSTAKA}

Ahmad, Kamaruddin. 2004. DasarDasar Manajemen Investasi dan Portofolio. Jakarta: PT Rineka Cipta.

Angka, Jordi. 2014. Money Management untuk Meningkatkan Keuntungan pada PT Victory Internasional Futures Malang cabang Letjend Sutoyo. Laporan Akhir tidak diterbitkan. Malang: Program Studi Manajemen Fakultas Ekonomi dan Bisnis Unuversitas Ma Chung.

Budi, Triton Prawira. 2008. Forex On-line Trading. Yogyakarta: Penerbit Cemerlang Publising

Djohanputro, Bramantyo. 2008. Manajemen Risiko Korporat Terintegrasi. Jakarta: PPM.

Djojosoedarso, Soeisno. 2003. Prinsip-prinsip Manajemen Risiko dan Asuransi Edisi Revisi. Jakarta: Salemba Empat.

Fahmi, Irham. 2010. Manajemen Risiko: Teroi, Kasus dan Solusi. Bandung: Alfabeta.

Forsagita, Endang "Analisis Fundamental Manajemen Investasi" (Online) http://eforsagita931994.blogspot 
.co.id/2015/06/analisis-

fundamental-manajemen-

investasi.html (diakses pada 5

Desember 2016).

http://www.foreximf.com/belajar-

forex/mahir/risk-managementmoney-management/feed/

(diakses pada 15 Oktober 2016).

http://www.forextradingvalas.com/st

rategi-khusus-trading-forex-

valas/(diakses 2 Februari 2017).

http://belajarforex.com/manajemen-

resiko.html (diakses 10 Oktober 2016).

http://.seputarforex.com/belajar/fore x/tingkat_dasar/pengenalan_das ar_forex.php (diakses 11 Oktober 2016).

http://www.studiforex.com (diakses 5 Desember 2016).

Halim, Abdul. 2005. Analisis Investasi. Jakarta: Salemba Empat.

Indrawati, Nanik. 2008. Aplikasi manajemen Risiko Pada Investasi Foreign Exchange (Forex). Skripsi tidak diterbitkan. Malang: Program Studi Manajemen Fakultas Ekonomi (FE) Universitas Islam Negeri Maulana Malik Ibrahim Malang.
Kusumasari, Riski. 2011. Analisis Manajemen Risiko pada Transaksi Mata Uang Asing di PT Monex Investindo Futures Cabang Solo. Tugas Akhir tidak diterbitkan. Surakarta: Program D-III Keuangan dan Perbangkan Fakultas Ekonomi Universitas Sebelas Maret Surakarta.

Kurniawan, Rahmad "Manajemen Risiko" "Online) http://berdoauntukmati.blogspot. co.id/2013/11/manajemenrisiko.html (diakses 10 Oktober 2016).

PT Bestprofit Futures Cabang Bandung "Cara Instalasi dan Setting Java" (Online) http://bestprofitfuturesbandung.blogspot.co.id/2 014/12/cara-instalasi-dansetting-java-PThtml (diakses 11 Oktober 2016).

PT Bestprofit Futures Cabang Malang "PT Bestprofit Futures Investing" (Online) http://www.bestprofitmalang.co $\mathrm{m} /$ (diakses 11 Oktober 2016).

Tandelilin, Eduardus. 2001. Analisis Investasi dan Manajemen Portofolio. Yogyakarta: BPFE. 